\title{
Comparison of cerclage and pessary in prevention of preterm birth in twin pregnancies
}

\author{
Nazanin Hajizadeh ${ }^{1}$, Nasrin Saharkhiz ${ }^{* 1}$, , Sedigheh Hosseini ${ }^{1}$, Behnam Arabzadeh $^{2}$
}

Received: 24 Mar 2019

\author{
Published: 6 Jul 2020
}

Abstract

Background: The preterm labor has increased in multiple pregnancies over the past 2 decades. Preterm labor has led to increase in neonatal mortality rates, long-term morbidity, respiratory distress, and neonatal infections. Thus, this study aimed at investigating the effect of cerclage versus pessary on the prevention of preterm birth in twin pregnancies.

Methods: This prospective randomized clinical trial was performed on 50 women pregnant with twins who visited Taleghani hospital in 2016-2018. Their cervical length, which was measured by transvaginal ultrasonography (TVS), was less than 30 millimeters at week 14 of pregnancy. The participants were randomly divided into 2 groups $(\mathrm{n}=25)$. They separately underwent cervical pessary and cerclage. McDonald's procedure was performed in cerclage group from 14 to 27 weeks. The suture material was Mersilene Ethicon 5-0 double-armed s14 needle. Ring hodge pessary was also inserted in the vagina of the participants in the pessary group. All the patients were injected $250 \mathrm{mg}$ intramuscular 17 alpha-hydroxyprogesterone caproate weekly from week 16 to week 36 . All statistical analyses were performed using SPSS 18 software.

Results: The results of this study showed that the mean \pm standard deviation (SD) for pregnancy length of the cerclage and pessary groups were 238.6 \pm 32.4 and 223.6 \pm 16.6 , respectively. Also, significant differences were found between the 2 groups $(p=0.048)$. No significant difference was found in pregnancy $(\mathrm{p}=0.565)$, length of pessary/cerclage use $(\mathrm{p}=0.491)$, and BMI before and after delivery between the cerclage and pessary groups $(\mathrm{p}>0.05)$.

Conclusion: The use of cerclage in twin pregnancies is recommended to increase the length of pregnancy.

Keywords: Cerclage, Pessary, Twin pregnancy

Conflicts of Interest: None declared

Funding: This study was supported by Research Vice-Chancellor of Shahid Beheshti University of Medical Sciences.

*This work has been published under CC BY-NC-SA 1.0 license.

Copyright $($ Iran University of Medical Sciences

Cite this article as: Hajizadeh N, Saharkhiz N, Hosseini S, Arabzadeh B. Comparison of cerclage and pessary in prevention of preterm birth in twin pregnancies. Med J Islam Repub Iran. 2020 (6 Jul);34:74. https://doi.org/10.47176/mjiri.34.74

\section{Introduction}

The preterm labor has increased in multiple pregnancies over the past 2 decades. Preterm labor has led to increase in neonatal mortality rates, long-term morbidity, respiratory distress, and neonatal infections (1). The risk of spontaneous preterm birth (SPTB) does not reduce with routine

Corresponding author: Dr Nasrin Saharkhiz, saharkhiz.n@sbmu.ac.ir

1. Preventation Gynecology Research Center, Imam Hossein Hospital, Shahid Beheshti University of Medical Sciences, Tehran, Iran

2. Anesthesiology Research Center, Shahid Beheshti University of Medical Sciences, Tehran, Iran cervical pessary treatment in women with twin pregnancy (2). In other studies, cervical cerclage in twin pregnancy did not prolong the length of pregnancy or improve neonatal outcomes (3). Results of a retrospective cohort of women with second-trimester cervical dilatation showed

$\uparrow$ What is "already known" in this topic:

Preterm labor has increased in multiple pregnancies over the past 2 decades, which have led to increase in neonatal mortality rates, long-term morbidity, respiratory distress, and neonatal infections. Some interventions are available for preventing preterm labor. Since cervical cerclage need surgery and has several side effects, cervical pessary is performed in some other centers.

\section{$\rightarrow$ What this article adds:}

In this study on the prevention of preterm birth in twin pregnancies, the efficacy of cervical cerclage versus cervical pessary is compared and appropriate intervention is recommended. 
that pessary outcomes were not superior to expectant management $(4,5)$. In one study, cervical pessary led to a significant increase in the length of pregnancy by 36 and 34 weeks, but no significant change was found in the pregnancies lasting less than 32 weeks (6). Since cervical cerclage need surgery and has several side effects, cervical pessary is performed in some other centers. Hence, this study aimed at investigating the effect of cerclage versus pessary in the prevention of preterm birth in twin pregnancies.

\section{Methods}

This was a prospective, randomized clinical trial in which cases were randomly assigned into 2 groups of 50 women with twin pregnancies who referred to Taleghani hospital in 2016-2018.

Their cervical length, which was measured by transvaginal ultrasonography (TVS), was less than 30 millimeters at the week 14 of pregnancy. Patients were randomly allocated to the pessary or cerclage group according to the last digit of their medical record number. Patients with odd numbers were assigned to the pessary group and patients with even numbers to cerclage group.

They separately underwent cervical pessary and cerclage. Procedure of the project was explained to the participants in detail and written informed consents were obtained from all. Inclusion criteria were twin pregnancy, para 1 and para 2, and 20 weeks $<$ gestational age $<40$ weeks. Exclusion criteria were uterine anomalies, chronic diseases (eg, rheumatism, kidney failure, and diabetes), recurrent miscarriage and maternal age $>40$, and history of preterm labor, cervical cerclage procedure, neonatal death, and painful contractions. Personal and clinical information on the mothers were age, weight, height, length of pregnancy, and type of delivery. The information on the infants including Apgar score, weight, and admission to ICU was recorded in a checklist. All the patients received 17- $\alpha$ hydroxyprogesterone caproate via IV injection weekly from the week 16th to 36th. McDonald's procedure was performed in cerclage group from 14 to 27 weeks. The suture material was Mersilene Ethicon 5-0 double-armed s14 needle. Ring hodge pessary was also inserted in vagina of women in the pessary group. The study protocol was approved by the ethics committee of Shahid Beheshti University of Medical Sciences (ethical code: IR.sbmu.msp.rec.1396.468). The study was registered in the IRCT (code: IRCT20170724035265N2). Frequency and percentage of each of the variables were calculated for the both groups and the relationship between quantitative independent or depended variables was examined using $t$ test. $\mathrm{P}<0.05$ was considered statistically significant.

\section{Results}

The results of the study showed that the mean \pm SD for age and maternal age of the pessary and cerclage groups was $29.52 \pm 4.55$ and $29.20 \pm 4.38$ years, respectively, with no significant differences between the 2 groups $(\mathrm{p}=0.801)$. No significant difference was observed in pregnancy $(p=0.565)$, length of pessary/cerclage use $(p=0.491)$, and BMI before and after delivery between the 2 groups ( $>0.05$ ). Moreover, the mean $\pm \mathrm{SD}$ for pregnancy length of the cerclage and pessary groups was $238.6 \pm 0.048$ and $223.6 \pm 16.6$, respectively, with significant differences between the 2 groups $(\mathrm{p}=0.048)$ (Table 1$)$.

\section{Discussion}

According to this study, cerclage can increase the length of pregnancy in mothers. Results of a retrospective study by Roman et al showed that women undergoing rescue cerclage had significantly better neonatal outcomes than those without cerclage (7). Also, Katarzyna KosinskaKaczynska et al found a significant relationship between use of cerclage and pessary and preference of cerclage over pessary in the length of pregnancy (8). However Alexis C. Gimovsky et al showed that pessary is preferred over cerclage (4). Results of a meta-analysis by Zheng L et al indicated that the risk of SPTB can be reduced and gestational age can be increased by the placement of pessary in multiple pregnancies before the week 34 th of gestation (9). In some studies, no significant relationship was found between pessary and improvement in pregnancy outcomes. Gimovsky AC et al found that pessary did not improve pregnancy outcomes in comparison to cerclage (4). Levakov et al performed pessary and cerclage in patients with cervical incompetence and found no difference between these 2 procedures (10). Also, Antczak-Judycka A. et al in a study on cerclage-pessary and cerclage alone treatments found no difference between these 2 methods (11). In a meta-analysis study, Saccone G. et al found that the risk of SPTB or perinatal outcome is not reduced following the use of Arabin pessary with short-transvaginal ultrasound cervical length in twin pregnancies during weeks 16th to 24th of gestation (12).

Bariono SV et al indicated that coadministration of progesterone and pessary could be more effective than other methods like cerclage (13). According to the results of a study by Jarde A. et al, overarching interventions cannot prevent SPTB and its outcomes, but some secondary outcomes are controlled via progesterone vaginal (14). Nevertheless, they did not examine the efficacy of progester-

Table 1. Descriptive data by pessary and cerclage and comparison between the 2 groups with research variables

\begin{tabular}{lccc}
\hline Variable & $\begin{array}{c}\text { Pessary Mean } \\
\text { (SD) }\end{array}$ & $\begin{array}{c}\text { Cerclage Mean } \\
(\text { SD) }\end{array}$ & P value \\
\hline Maternal age & $29.52(4.55)$ & $29.20(4.38)$ & 0.801 \\
Pregnancy & $1.32(0.47)$ & $1.40(0.50)$ & 0.565 \\
Length of pessary/cerclage use & $16.80(2)$ & $17.28(2.82)$ & 0.491 \\
Pregnancy length & $223.6(16.6)$ & $238.6(32.6)$ & 0.048 \\
BMI (before pregnancy) & $30.37(6.81)$ & $30.66(3.67)$ & 0.736 \\
BMI (before pregnancy) & $27.43(3.80)$ & $27.08(3.54)$ & 0.83 \\
SD: Stancer Power & 0.89 \\
\hline
\end{tabular}

SD: Standard deviation 
one in the prevention of preterm labor. Thus, investigating simultaneous use of pessary and medication therapy is recommended to prevent preterm labor in large group studies.

\section{Conclusion}

The use of cerclage in twin pregnancies is recommended to increase the length of pregnancy. However, further large-scale randomized controlled trials are required to obtain more conclusive results.

\section{Conflict of Interests}

The authors declare that they have no competing interests.

\section{References}

1. D'antonio F, Thilaganathan B, Dias T, Khalil A. Influence of chorionicity and gestational age at single fetal loss on risk of preterm birth in twin pregnancy: analysis of STORK multiple pregnancy cohort. Ultrasound Obstet Gynecol. 2017;50(6):723-727.

2. Nicolaides KH, Syngelaki A, Poon LC, Picciarelli G, Tul N, Zamprakou A. A randomized trial of a cervical pessary to prevent preterm singleton birth. N Engl J Med. 2016;374(11):1044-1052.

3. Eskandar M, Shafiq H, Almushait MA, Sobande A, Bahar AM. Cervical cerclage for prevention of preterm birth in women with twin pregnancy. Int J Gynaecol Obstet. 2007;99 (2):110-112.4.

4. Gimovsky AC, Suhag A, Roman A, Rochelson BL, Berghella V. Pessary versus cerclage versus expectant management for cervical dilation with visible membranes in the second trimester. J Matern Neonatal Med. 2016;29(9):1363-1366.

5. Saccone G, Rust O, Althuisius S, Roman A, Berghella V. Cerclage for short cervix in twin pregnancies: systematic review and meta analysis of randomized trials using individual patient level data. Acta Obstet Gynecol Scand. 2015;94(4):352-358.6.

6. Di Tommaso M, Seravalli V, Arduino S, Bossotti C, Sisti G, Todros T. Arabin cervical pessary to prevent preterm birth in twin pregnancies with short cervix. J Obstet Gynaecol. 2016;36(6):715-718.7.

7. Roman A, Rochelson B, Martinelli P, Saccone G, Harris K, Zork N, et al. Cerclage in twin pregnancy with dilated cervix between 16 to 24 weeks of gestation: retrospective cohort study. Am J Obstet Gynecol. 2016;215(1):98. e91-98. e11.

8. Kosinska-Kaczynska K, Bomba-Opon D, Zygula A, Kaczynski B, Wegrzyn P, Wielgos M. Adjunctive pessary therapy after emergency cervical cerclage for cervical insufficiency with protruding fetal membranes in the second trimester of pregnancy: a novel modification of treatment. BioMed Res Int. 2015;2015:185371.

9. Zheng L, Dong J, Dai Y, Zhang Y, Shi L, Wei M, et al. Cervical pessaries for the prevention of preterm birth: a systematic review and meta-analysis. J Matern Fetal Neonatal Med. 2019;32(10):1654-1663.

10. Levakov SA, Borovkova EI, Sheshukova NA, Borovkov IM. Management of patients with cervical insufficiency. Obstet Gynecol Reprod. 2016;2;10(2):64-9.

11. Antczak-Judycka A, Sawicki W, Spiewankiewicz B, Cendrowski K, Stelmachów J. Comparison of cerclage and cerclage pessary in the treatment of pregnant women with incompetent cervix and threatened preterm delivery. Ginekol Pol. 2003;74(10):1029-1036.

12. Saccone G, Ciardulli A, Xodo S, Dugoff L, Ludmir J, D’Antonio F, et al. Cervical pessary for preventing preterm birth in twin pregnancies with short cervical length: a systematic review and metaanalysis. J Matern Fetal Neonatal Med. 2017;30(24):2918-2925.

13. Barinov SV, Shamina IV, Lazareva OV, Tirskaya YI, Ralko VV, Shkabarnya LL, et al. Comparative assessment of arabin pessary, cervical cerclage and medical management for preterm birth prevention in high-risk pregnancies. J Matern Fetal Neonatal Med. 2017;30(15):1841-1846.

14. Jarde A, Lutsiv O, Park CK, Barrett J, Beyene J, Saito S, et al. Preterm birth prevention in twin pregnancies with progesterone, pessary, or cerclage: a systematic review and meta-analysis. Int J Obstet Gynaecol. 2017;124(8):1163-73. 